\title{
Dynamic Transcriptional Profiles of Arabidopsis thaliana Infected by Tomato spotted wilt virus
}

\author{
Min Xu, Jing Chen, Ying Huang, Danyu Shen, Peng Sun, Yi Xu, ${ }^{\dagger}$ and Xiaorong Tao ${ }^{\dagger}$ \\ Department of Plant Pathology, Nanjing Agricultural University, Nanjing 210095, People's Republic of China \\ Accepted for publication 18 September 2019.
}

ABSTRACT

\begin{abstract}
Tomato spotted wilt virus (TSWV) is a negative-stranded RNA virus that infects hundreds of plant species, causing great economic loss. Infected Arabidopsis thaliana plants develop symptoms including chlorosis and wilt, which can lead to cell death. From 9 to 15 days after TSWV infection, symptoms progress through a three-stage process of appearance, severity, and death. In this study, deep sequencing technology was first used to explore gene expression in response to TSWV infection in model plant $A$. thaliana at different symptom development stages. We found that plant immune defense and protein degradation are induced by TSWV infection and that both inductions became stronger over time.
\end{abstract}

The photosynthesis pathway was attenuated with TSWV infection. Cell wall metabolism had a large extent of downregulation while some genes were upregulated. These results illustrate the dynamic nature of TSWV infection in A. thaliana at the whole-transcriptome level. The link between biological processes and subpathway metabolism was further analyzed. Our study provides new insight into host regulatory networks and dynamic processes in response to TSWV infection.

Keywords: Arabidopsis thaliana, cell wall, deep sequencing, photosynthesis, plant defense, protein degradation, transcriptome, TSWV
Tomato spotted wilt virus (TSWV) is a negative-stranded RNA virus of the genus Orthotospovirus, the family Tospoviridae, and the order Bunyavirales. TSWV is widely distributed throughout the world and can cause huge economic losses by infecting a range (>800) of plant species, including tomato, pepper, lettuce, peanut, and chrysanthemum (Oliver and Whitfield 2016; Scholthof et al. 2011; Turina et al. 2016). In nature, TSWV is transmitted mainly by western flower thrips (Frankliniella occidentalis) in a persistent and propagative manner (Gilbertson et al. 2015; Rotenberg et al. 2015). Western flower thrips are difficult to control because they are small and often concealed in buds, where they feed on plant pollen and organs. TSWV is considered the second most scientifically or economically important plant virus (Scholthof et al. 2011). Plant stems, leaves, and fruits develop severe symptoms after viral infection. In the early stages, leaves and fruits display chlorotic rings, mottling, and flecking, which progress to stunting necrosis. Finally, the whole plant becomes wilted and dies (Prins and Goldbach 1998). In China, TSWV is distributed mainly in the southwestern area, and the virus causes serious harm within the tomato industry, leading to losses of up to nearly $100 \%$ (Hu et al. 2011).

The TSWV genome is composed of three RNA segments, which are 9, 4.8, and $3 \mathrm{~kb}$ in size. The large (L) segment encodes an RNAdependent RNA polymerase. The medium (M) segment encodes the NSm protein and the precursor of glycoprotein. NSm is a movement protein that localizes at the endoplasmic reticulum and plasmodesmata to facilitate viral cell-to-cell movement (Feng et al. 2016). The

†Corresponding authors: X. Tao; taoxiaorong@njau.edu.cn, and Y. Xu; xuyiqdpd@njau.edu.cn

Funding: This work was supported by grants from the National Natural Science Foundation of China (31630062 and 31870143), the Fundamental Research Funds for the Central Universities (JCQY201904), and the Youth Science and Technology Innovation Program (to $\mathrm{X}$. Tao).

*The $e$-Xtra logo stands for "electronic extra" and indicates two supplementary figures and six supplementary tables are published online.

The author(s) declare no conflict of interest.

(c) 2020 The American Phytopathological Society small (S) segment encodes the NSs nonstructural protein and the $\mathrm{N}$ protein. NSs is a gene-silencing suppressor that can bind microRNA and small interfering RNA (siRNA) duplexes, as well as long double-strand RNAs (dsRNAs) that inhibit the cleavage of viral dsRNAs from Dicer protein (Hedil et al. 2015, 2017). N protein is a nucleocapsid protein that is able to move along actin with the help of XI-K, and it can bind and protect viral RNA in vivo (Feng et al. 2013; Li et al. 2015). The $\mathrm{L}$ segment is composed of negativesense RNA, whereas the other two segments are composed of ambisense RNAs.

Plant viruses are obligate parasites that require host machinery to accomplish multiplication. Plant metabolic pathways change dynamically during viral infection (De Vos et al. 2005; Mochizuki et al. 2014; Prasch and Sonnewald 2013). In turn, host plants have evolved various means of preventing the infection of viruses (Petek et al. 2014; Shi et al. 2013; Su et al. 2016; Zhu et al. 2019). Previous studies have shown that viruses can induce metabolic changes during interactions with host plants. For example, in pea plants, the expression patterns of genes involved in chloroplastic metabolism change to release reactive oxygen species (ROS) in response to Plum pox virus infection (Diaz-Vivancos et al. 2008; Rubio et al. 2015). Differential expression patterns are observed in both resistant and susceptible tomato cultivars infected with Tomato yellow leaf curl virus (TYLCV) (Sade et al. 2014). TSWV triggers plant ROS accumulation in hypersensitive and susceptible Solanaceae hosts (Quecini et al. 2007). In insect host whitefly, global transcriptional response after TYLCV infection was also analyzed and those pathways related to virus-host interaction were identified (Luan et al. 2011). Also taking TYLCV as an example, the autophagy pathway was shown to contribute to inhibition of viral infection in whitefly (Wang et al. 2016). From a viral aspect, BV1 protein could subvert plant resistance through interacting with transcriptional factor MYC2 (Li et al. 2014).

The development of RNA-sequencing (RNA-seq) techniques has provided new insights into host gene transcriptional changes during biotic and/or abiotic stress (Wang and Liu 2009). This technology has been widely used to study changes in gene expression in virus-host interactions (Geng et al. 2017; Ke et al. 2014; Miozzi et al. 2014; Wang et al. 2011; Yates et al. 2014; Ye et al. 2011; Yu 
et al. 2012). For example, analyses of gene expression changes in Plum pox virus-infected peach leaves revealed the complicated expression process for Sharka symptoms (Rubio et al. 2015). Comparative gene expression analyses have shown that primary metabolism and ubiquitin-proteasome pathways in Sogatella furcifera are perturbed by infection with Southern rice blackstreaked dwarf virus (Xu et al. 2012). For tospoviruses, microarray assays were performed on Nicotiana benthamiana plants infected with Sonchus yellow net virus and Impatiens necrotic spot virus (Senthil et al. 2005). Padmanabhan et al. (2019) performed transcriptome analysis on tomato carrying resistance gene $S w-7$ in response to TSWV infection and found that callose accumulation, lignin deposition, and transcriptional activation/ repression may be involved in $S w$-7-mediated resistance against TSWV. Likewise, microarray assays on analysis of specific and common gene expression changes in hosts infected with TSWV and other RNA viruses were performed in Dendranthema grandiflorum Ramatuelle 'Shinma' (Choi et al. 2015) as well as in tomato shoots and roots (Catoni et al. 2009). Transcriptomewide identification of tomato genes targeted by TSWV-derived siRNAs were analyzed in tomato plant, revealing potential targets of host genes involved in primary and secondary metabolism and their roles in pathogenicity (Ramesh et al. 2017). To study the whole-transcriptional response in insect vectors after carrying TSWV, RNA-seq was performed to analyze the transcriptome profile at different host developmental stages in $F$. occidentalis (Schneweis et al. 2017) and those transcripts involved in virus transmission and insecticide resistance were also analyzed (Zhang et al. 2013). However, deep sequencing technology has not yet been used to investigate virus-plant host interactions at different infection points between type species TSWV and Arabidopsis thaliana. The alteration of host gene expression in plants from the initial TSWV infection to plant death remains poorly understood.

A. thaliana is one of the most studied host plants used to explore mechanisms of interaction with pathogens and it plays an important role in research on pathogenicity and the plant immune response (Asari et al. 2017; Huang et al. 2016; Martínez-Pérez et al. 2017; Raad et al. 2019; Zhang et al. 2015). TSWV is able to infect the model plant $A$. thaliana (German 1995). In this study, deep sequencing RNA-seq was performed to analyze the differentially expressed genes (DEGs) at 9, 12, and 15 days postinoculation (dpi) in A. thaliana after TSWV infection. Key genes were comprehensively identified and classified into essential pathways, providing new insight into TSWV pathogenesis and the host immune response. Our research illustrates the symptom development process in light of global transcriptome reprogramming after TSWV infection.

\section{MATERIALS AND METHODS}

Plant material and virus inoculation. A. thaliana ecotype Col-0 was grown in growth chambers (Jiangnan Motor Factory, Ningbo, China) at $22^{\circ} \mathrm{C}$ with an 8 -h/16-h light/dark cycle. TSWV was maintained in $N$. benthamiana plants. Six- to 8-week-old plants were used for viral inoculation. TSWV-infected $N$. benthamiana leaves were collected and ground in $\mathrm{PB}$ buffer $(0.01 \mathrm{M}$ of $\mathrm{Na}_{2} \mathrm{HPO}_{4} \cdot \mathrm{H}_{2} \mathrm{O}$ and $0.01 \mathrm{M}$ of $\mathrm{Na}_{2} \mathrm{H}_{2} \mathrm{PO}_{4} \cdot 2 \mathrm{H}_{2} \mathrm{O}, \mathrm{pH}$ 7.5) to inoculate $A$. thaliana. The negative control was inoculated with PB buffer only.

RNA isolation and RNA-seq library preparation. For TSWV-infected plants or mock-inoculated plants, three biological replicates of samples were collected at each 9, 12, and 15 dpi timepoint. For each biological replicate, systemically infected leaves from three Arabidopsis plants were collected and combined as one sample. In total, 18 leaf samples were obtained. Total RNA of systemically infected $A$. thaliana leaves was extracted using a Total RNA Extraction Kit (Tiangen Biotech). For each sample, total RNA was used to construct the mRNA-seq library according to the TrueSeq RNA Sample Prep Kit protocol (Illumina). Library quality control and quantification were performed using the Experion DNA $1 \mathrm{~K}$ Chip (Bio-Rad) and Qubit fluorometer (Invitrogen), respectively. In total, 18 libraries were generated; for each library, 75 million 100-bp paired-end sequences were generated using an Illumina HiSeq 2500 sequencer (BGI).

Quantitative real-time PCR. Total RNA from systemically infected A. thaliana was used to synthesize first-strand cDNA using a PrimeScript RT reagent kit with gDNA eraser (Takara). Then the cDNA was amplified using Power SYBR Green Master Mix (Life Technologies). Primers used in quantitative real-time PCR (qRTPCR) for validation of DEGs are listed in Supplementary Table S1. qRT-PCR was performed using an Applied Biosystems 7500 Real-Time PCR system (Life Technologies). A. thaliana actin and elongation factor $\mathrm{EF} 1 \alpha$ served as internal controls to normalize the RNA levels of target genes between samples.

Reads mapping and annotations. A total of 18 RNA libraries were sequenced, and reads obtained from the sequencing machines were further filtered by fastp (version 0.18.0). Adaptors and reads containing $>10 \%$ of unknown nucleotides $(\mathrm{N})$ and of low quality ( $>50 \%$ of low quality, $\mathrm{Q}$ value $\leq 20$ ) were removed. The produced clean reads then were mapped to the ribosome RNA database by using the Bowtie alignment algorithm allowing zero mismatch (Langmead and Salzberg 2012) and these mapped reads were then removed. Clean data were mapped to the A. thaliana reference genome (http://mapman.gabipd.org/) using TopHat software (Trapnell et al. 2009) and then quantified using Cufflinks version 1.0.3 (Trapnell et al. 2010). The expression level of each gene was output as fragments per kilobase of exon per million fragments mapped (FPKM) values, and Poisson distribution was used to test the $P$ value. Groups of three biological replicates were combined and the DEGs were identified using DEGseq (Trapnell et al. 2010). We then used Poisson distribution to test the $Q$ value (false discovery rate) (Benjamini and Hochberg 1995), and Q values $<0.05$ were considered statistically significant and used for further analysis. To filter out weakly expressed genes, only genes with FPKM values $>1$ were included in the analyses. Genes with twofold or greater changes $\left(\log _{2}\right.$ ratio $\left.\geq 1\right)$ in expression compared with controls were considered differentially expressed. Raw data of this experiment were submitted to the China National GeneBank (https://www.cngb.org/index.html; project number CNP0000645).

Software and websites used for analyses. The MapMan ontology tool was used to obtain an overview of $A$. thaliana genes involved in metabolic pathways. MapMan uses a plant-specific ontology that classifies genes into well-defined hierarchical categories, designated BINs (http://mapman.gabipd.org/). A. thaliana genes identified in our research were assigned to BINs using the Mercator automated annotation pipeline. To cluster the data based on relationships among gene expression-level variables in the data at different timepoints and to find the relationship of different gene expression patterns, $\mathrm{MeV}$ software was used for nonsupervised clustering analyses of selected expression data with Euclideanrelated metrics (Manhattan distance) and a complete clustering algorithm (TIGR MeV software package) (Saeed et al. 2003). The agriGO (http://bioinfo.cau.edu.cn/agriGO/) and Bioinformatics and Evolutionary Genomics (http://bioinformatics.psb.ugent.be/ webtools/Venn/) websites were used to generate Gene Ontology (GO) annotation images and Venn diagrams.

\section{RESULTS}

Symptom development in TSWV-infected A. thaliana. A. thaliana plants were mechanically inoculated with TSWV ground from infected $N$. benthamiana leaves, and the symptom development process was observed (Fig. 1). At 9 dpi, small yellow necrotic spots appeared on inoculated leaves, and no symptoms were 
observed on top leaves (Fig. 1A). By 12 dpi, yellow necrotic spots had spread over entire leaves, whereas top leaves began to display a light-yellow appearance (Fig. 1A). At $15 \mathrm{dpi}$, inoculated leaves were dying, and the systemically infected leaves developed curl and yellowing wilt symptoms, indicating that the entire plant was undergoing systematic death (Fig. 1A). At these three stages, all TSWV-infected plants exhibited stunting to some extent compared with mock-inoculated plants (Fig. 1). To compare changes in metabolic regulation between different stages after virus infection, three biological replicates of each stage were prepared for genomewide sequencing using RNA-seq. For each biological replicate, we collected systemically infected leaves of three different plants for RNA extraction. To validate successful virus infection, qRT-PCR was performed to detect TSWV nucleocapsid (N) mRNA accumulation for each biological replicate (Fig. 1B). TSWV was

A

MOCK
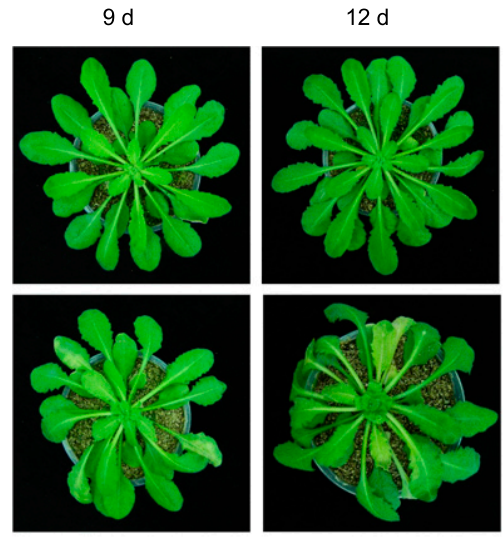

B

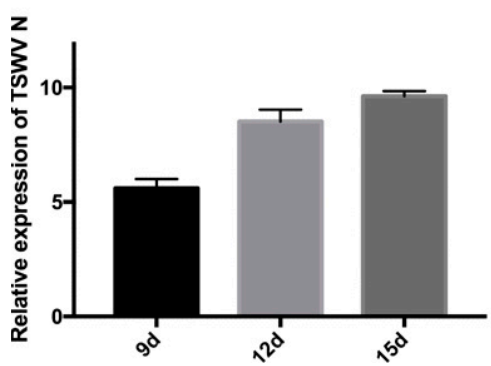

Fig. 1. Symptoms of Tomato spotted wilt virus (TSWV)-infected Arabidopsis thaliana plants. A, The top row represents symptoms in mock-inoculated plants at 9, 12, and 15 days postinoculation (dpi), respectively. The bottom row represents symptoms in TSWV-inoculated plants at 9, 12, and $15 \mathrm{dpi}$, respectively. B, Quantitative real-time PCR analysis of viral accumulation in Arabidopsis plants infected by TSWV at 9, 12, and 15 dpi, respectively. The $x$ axis represents the different time stages and the $y$-axis represents the signal intensity of each target gene as normalized with the reference gene.
A

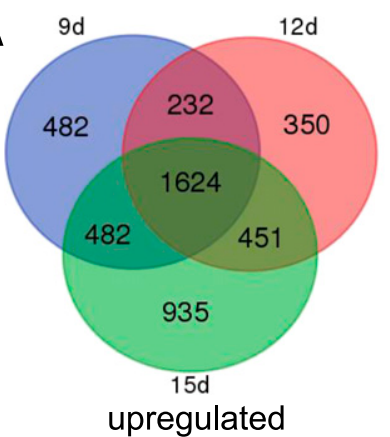

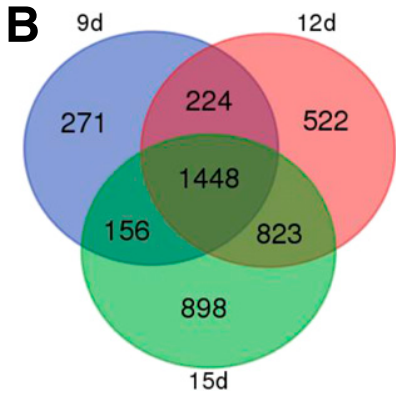

downregulated
Fig. 2. Venn diagrams of shared and unique differentially expressed transcripts at the three developmental stages. A, Upregulated transcripts. B, Downregulated transcripts. Blue represents transcripts at 9 days postinoculation (dpi), red represents transcripts at $12 \mathrm{dpi}$, and green represents transcripts at 15 dpi. detected on all inoculated samples and viral accumulation at 12 and 15 dpi was much higher than at 9 dpi (Fig. 1B); no virus was detected on healthy plants. The variation in TSWV $\mathrm{N}$ mRNA accumulation among three replicate plants in one group was very low, indicating that all biological replicates had a similar virus content (Fig. 1B).

Overview of expression patterns of DEGs in infected plants at different stages. A total of 18 RNA libraries were sequenced; within each library, $>86 \%$ of reads were mapped to the A. thaliana reference (Supplementary Table S1). In total, we identified 33,279 transcripts and obtained 8,916 DEGs in three libraries (Supplementary Table S2). These included 5,004, 5,798, and 6,913 DEGs at 9, 12, and 15 dpi, respectively (Supplementary Table S3).

We identified 3,072 genes with consistent expression across the three different stages (Fig. 2). Among them, 1,624 genes were upregulated and 1,448 genes were downregulated at all three timepoints. Some genes were differentially expressed at only a single timepoint: 482, 350, and 935 genes were upregulated only at 9,12 , and $15 \mathrm{dpi}$, respectively, whereas 271,522 , and 898 genes were downregulated only at 9,12 , and $15 \mathrm{dpi}$, respectively.

In addition to genes that were consistently regulated at different timepoints, some genes showed variable expression patterns. To identify other gene expression patterns, 5,103 genes were analyzed using MEV software to reveal the expression patterns of individual genes (Supplementary Table S4). Genes with similar expression patterns were clustered, resulting in four groups of gene expression patterns (Fig. 3). Genes clustered in group 1 showed up-up-downregulation and genes in group 2 showed down-stable-upregulation of gene expression at 9, 12, 15 dpi, respectively. In groups 3 and 4, genes showed a down-up and updownregulation pattern of gene expression at 9 and $15 \mathrm{dpi}$, respectively. Genes in both groups 3 and 4 showed downregulation at 12 dpi.

GO enrichment and metabolic pathway analyses of transcriptional responses to TSWV infection. To elucidate the physiological changes at three different timepoints of TSWV infection on a macroscale, the agriGO analysis tool was used for parametric analysis of gene set enrichment (PAGE) for upregulated and downregulated genes. GO enrichment classification revealed that the DEGs were associated with a range of biological processes, molecular functions, and cellular component

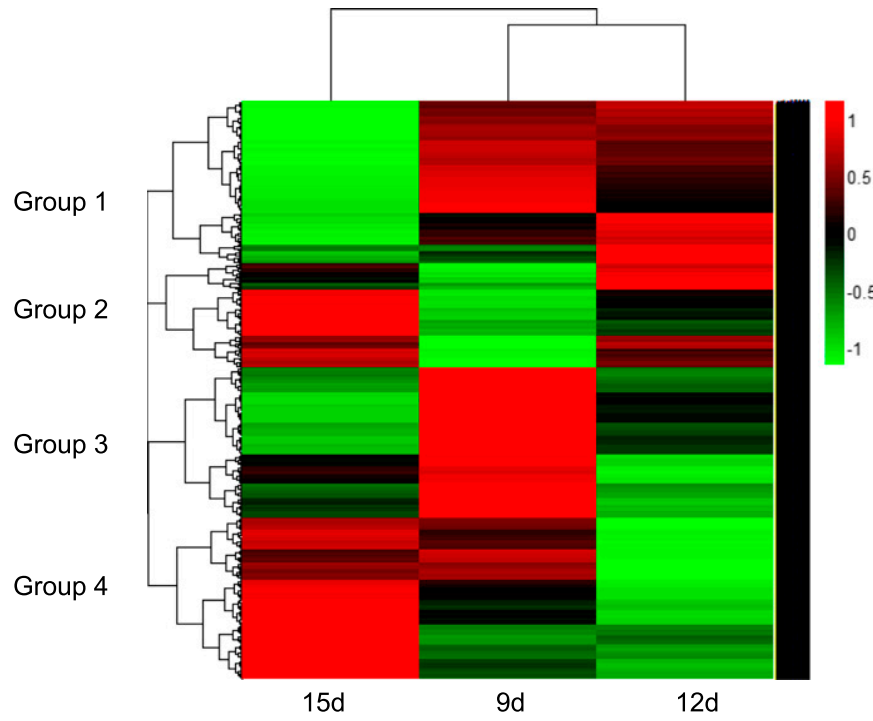

Fig. 3. Hierarchical clustering of 5,102 differentially expressed genes (DEGs) at different timepoints. $\log _{2}$ (fold change) values $>1$ were used. Fold changes from -1 to 1 are shown in gradients from green (light gray) to red (dark gray). The left lane represents DEGs at 15 days postinoculation (dpi), the middle lane represents DEGs at $9 \mathrm{dpi}$, and the right lane represents DEGs at $12 \mathrm{dpi}$. 
categories. PAGE analyses were used to compare several rows of DEGs simultaneously using the central limit theorem (Fig. 4) and the detailed information is listed in Supplementary Table S5. At 9 dpi, the top five most strongly induced pathways were cell killing, death, multiorganism process, stimulus response, and immune system process. The top five most strongly inhibited pathways were ellular component organization, cell wall organization or biogenesis, macromolecular process, organelle part, and structural molecule activity. Compared with the 9 dpi timepoint, pathways at 12 dpi were moderately regulated. Cell killing, death, and the immune system process were also induced. Organelle and extracellular region part were relatively inhibited. At $15 \mathrm{dpi}$, the signaling process and transcription regulator activity were induced, whereas cell wall organization, extracellular region, organelle part, and catalytic activity were inhibited (Fig. 4).

The MapMan tool was then used to present individual gene responses and their related metabolic pathways. Hotspot diagrams of each gene at 9, 12, and 15 dpi are shown in Supplementary Table S2. The photosynthesis pathway tended to be incrementally repressed, consistent with the phenotype of chlorosis and wilt on leaves (Supplementary Fig. S1). Cell wall modification and amino acid synthesis were also repressed. By contrast, genes related to lipid metabolism exhibited induced expression. In the secondary metabolism pathway, terpene synthase genes were incrementally repressed, whereas phenylpropanoid pathway genes were incrementally induced (Supplementary Fig. S1). These results represent an overview of changes to cellular metabolic pathways in response to TSWV infection at different points in time.

Photosynthesis is inhibited by TSWV infection. As shown in Supplementary Figure S1, metabolic pathway analyses showed that photosynthesis was downregulated after TSWV infection. Nonsupervised clustering analyses were performed to obtain a more precise overview (Fig. 5). The expression of genes in the photosynthesis pathway was mostly downregulated, and all downregulated genes exhibited similar expression patterns regardless of the amplitude of the variation. We noticed an increasing fold change over time after viral infection (Fig. 5A). At 9 dpi, the photosynthesis pathway exhibited mild downregulation, which became stronger at 12 dpi. At $15 \mathrm{dpi}$, the entire photosynthesis pathway was nearly completely shut down, as indicated by lower expression levels (Fig. 5). For instance, ribulose bisphosphate carboxylase small chain $1 \mathrm{~A}$ (At1g67090), which is a rubisco small subunit that plays a role in copper ion binding, was downregulated from an FPKM value of $23,581.5$ to $7,752.3$ at $9 \mathrm{dpi}$, from $20,853.4$ to $4,349.6$ at $12 \mathrm{dpi}$, and from 24,692.6 to 3,075.6 at 15 dpi (Supplementary Table S2). Phosphoglycerate kinase 1 (At3g12780), a phosphoglycerate kinase, decreased in FPKM value from 946 to 310 at 9 dpi, 1,020 to 221.5 at $12 \mathrm{dpi}$, and $1,473.6$ to 171.1 at $15 \mathrm{dpi}$. Chaperonin 60 beta

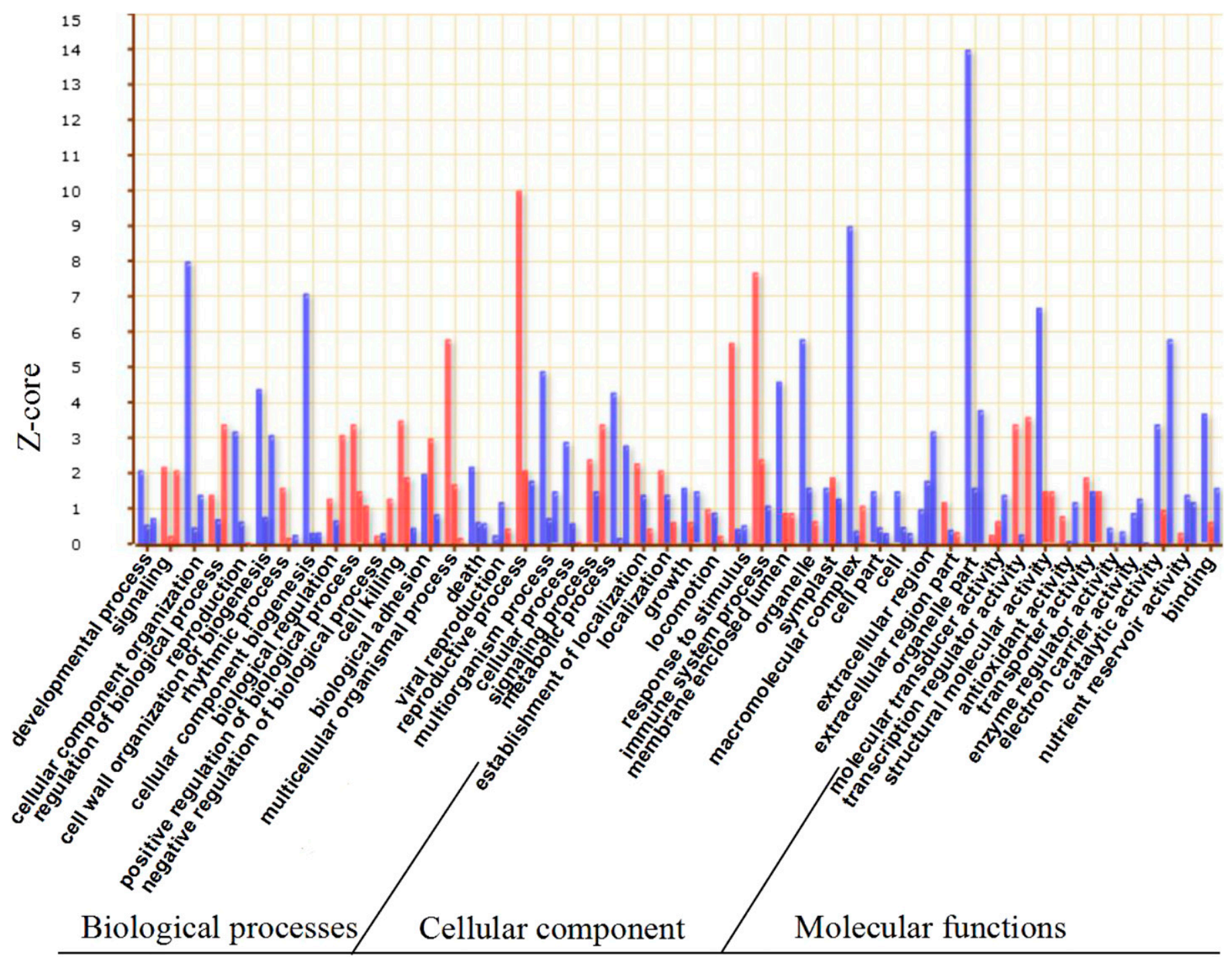

Fig. 4. Gene Ontology annotation results for differentially expressed genes (DEGs). Forty-six subpathways are listed on the $x$-axis below the bar chart. The three bars in each subpathway represent DEGs at 9, 12, and 15 days postinoculation. Z-core represents DEG values calculated in each group. Red (light gray) indicates upregulation and blue (dark gray) indicates downregulation. 
(Atlg55490), an ATP binding protein, decreased in FPKM value from 361.5 to 72 at $9 \mathrm{dpi}, 245.5$ to 28.3 at $12 \mathrm{dpi}$, and 389.5 to 18 at 15 dpi. Interestingly, the light-harvesting complex II subpathway exhibited a different expression pattern in which gene expression increased at $15 \mathrm{dpi}$. In total, nearly $70 \%$ of genes in photosystem I were downregulated (Fig. 5B). In addition, genes in photosystem II (PSII) and the Calvin cycle increased in expression by $70 \%$ at 9 dpi and $80 \%$ at 12 and $15 \mathrm{dpi}$. A number of genes had moderately attenuated expression levels at 12 and 15 dpi. Collectively, these results indicate that photosynthesis-related pathways were gradually shut down after TSWV infection.

Effects on the transcription of genes that regulate the cell wall. The plant cell wall is composed of cellulose, hemicellulose, pectin, and soluble proteins, which together provide structural support and help maintain cell shape (Fig. 6A). As shown in Figure 6, most DEGs related to cell wall regulation followed a similar expression pattern at 9, 12, and $15 \mathrm{dpi}$. A great number of the cell wall metabolic pathway-related genes were largely downregulated. Statistical analyses showed that about $30 \%$ of the DEGs related to cellulose synthesis were downregulated at $9 \mathrm{dpi}$, whereas $35 \%$ were downregulated at $12 \mathrm{dpi}$ and $45 \%$ were downregulated at
15 dpi (Supplementary Table S2). Other cell wall subpathways also had decreasing expression from 9 to $12 \mathrm{dpi}$ and showed a similar trend at 12 and $15 \mathrm{dpi}$. In addition, about $40 \%$ of genes related to cell wall degradation and modification were downregulated. Nearly $40 \%$ of genes in the arabinogalactan protein (AGP) and pectin esterase subpathways were also downregulated (Supplementary Table S2). Among the downregulated genes, cellulose synthesisrelated genes belonging to the cellulose synthase family were globally inhibited, including cellulose synthesis like C2 (At5g22740) and cellulose synthesis like C5 (at4g31590). AGP4 (At5g10430) and AGP7 (At5g65390), members of the cell wall arabinogalactan protein family, were also downregulated. The fold changes for AGP4 were 1.7, 2.8, and 2.9 at 9, 12, and $15 \mathrm{dpi}$, respectively. The fold changes for AGP7 were 1.6, 1.7, and 1.6 at 9, 12 , and $15 \mathrm{dpi}$, respectively. Interestingly, among upregulated genes, several cell wall degradation enzymes were strongly induced (Table 1). The FPKM value of beta-1,3-glucanase 1 (At3g57260), a glucan degradation enzyme, increased from 13 to 1,459 at 9 dpi, from 229.6 to $2,461.4$ at $12 \mathrm{dpi}$, and from 311 to 1,365 at $15 \mathrm{dpi}$. The corresponding fold changes were $6.8,3.4$, and 2.1 , respectively. This gene encodes pathogenesis-related (PR) proteins, which play
A

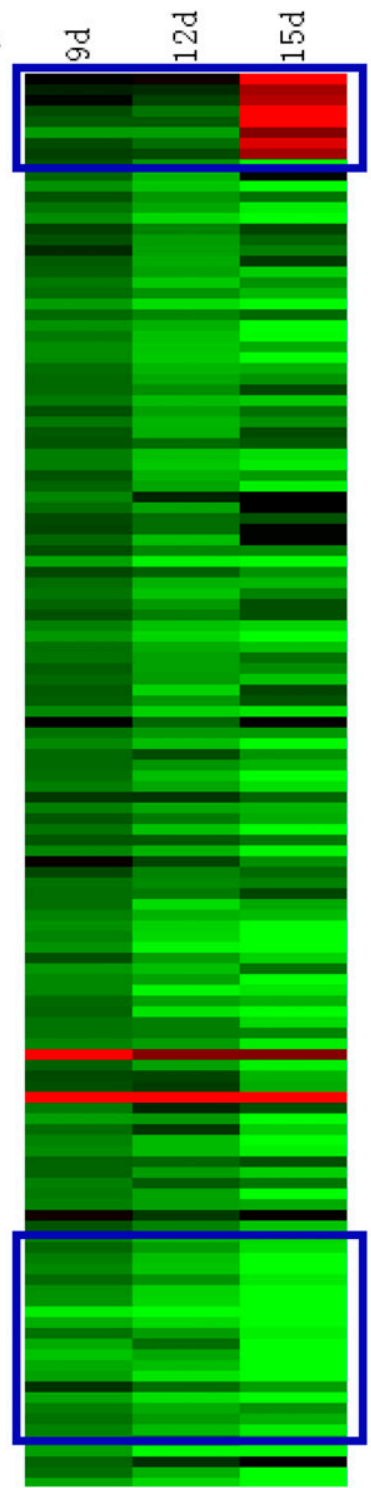

B

\section{Photosynthesis metabolic changes}

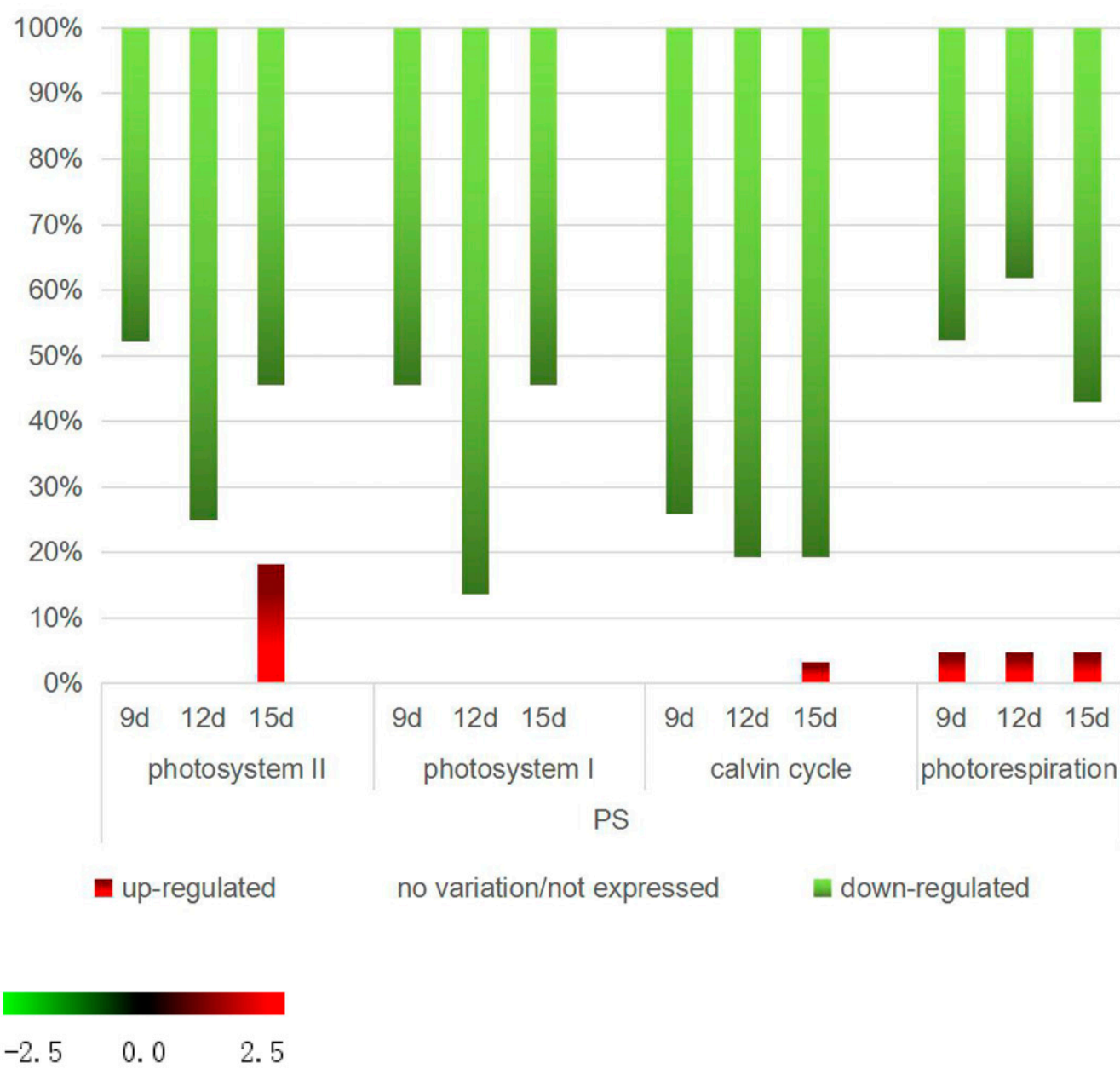

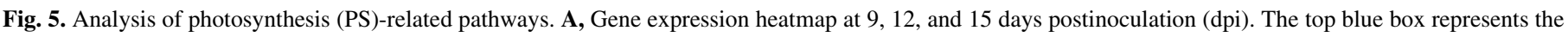

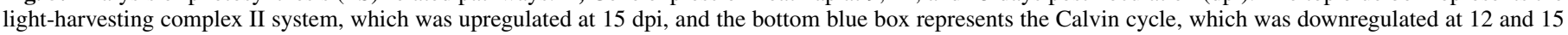

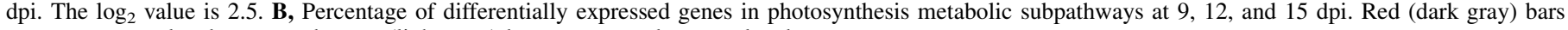
represent upregulated genes and green (light gray) bars represent downregulated genes. 
roles in plant defense against pathogens (Edelbaum et al. 1991). The FPKM value of xyloglucosyl transferase (At4g30270) increased from 20.3 to 187 at $9 \mathrm{dpi}, 22$ to 172 at $12 \mathrm{dpi}$, and 16.7 to 272.4 at $15 \mathrm{dpi}$. Another cellulase glycosyl hydrolase family 17 protein (At2g27500) was induced to a more moderate

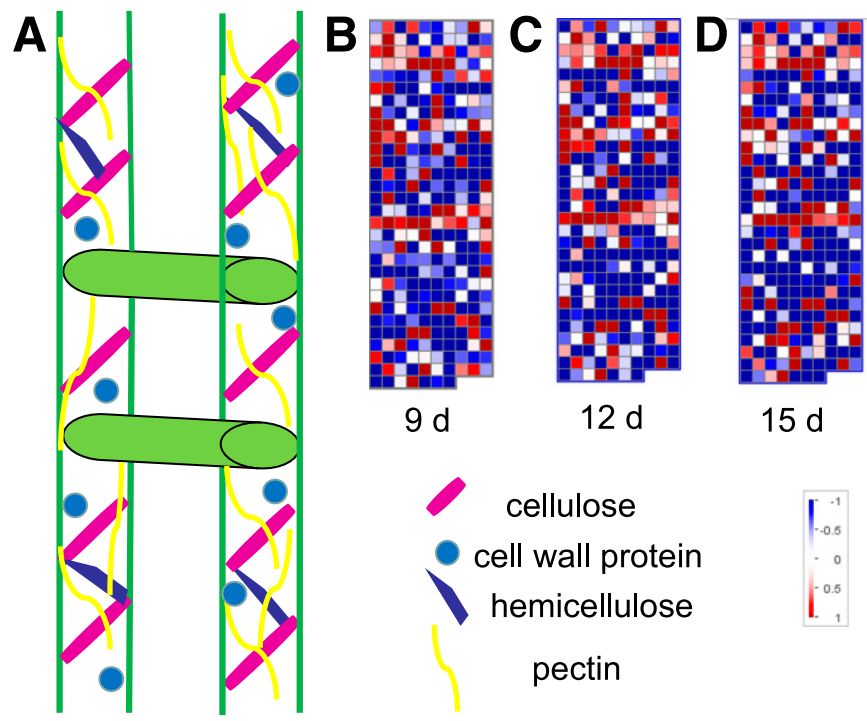

Fig. 6. Differentially expressed genes (DEGs) involved in cell wall synthesis and degradation. A, A model of the cell wall structure. B, C, and D, Heatmap images of DEGs at 9,12 , and 15 days postinoculation, respectively. extent, exhibiting 1.5-, 1.3-, and 1.1-fold changes in transcriptional expression at 9,12 , and $15 \mathrm{dpi}$, respectively. These results indicate that cell wall metabolic activity declined at all three timepoints, which may impair cell structure and lead to metabolic deficiency.

Activation of ubiquitin-proteasome, autophagy, and plant defense responses. Plants have evolved many defense responses to counteract TSWV infection (Zhu et al. 2019). In hormone signaling pathways, abscisic acid and ethylene influence plant resistance to pathogens (Baccelli and Mauch-Mani 2016; Kachroo and Kachroo 2007; Mauch-Mani and Flors 2009). In this study, we found that both abscisic acid and ethylenerelated genes were upregulated. At $15 \mathrm{dpi}$, their expression had increased by approximately 35\% (Fig. 7). Gibberellins and auxins had a balance of downregulated and upregulated genes. PR proteins and heat-related pathways play an essential role in stress metabolism (Aparicio et al. 2005; Chandrasekaran and Chun 2016; Lu et al. 2003). We found that stimulus- and stress response-related pathways were significantly enriched with DEGs (Fig. 7). Almost 20\% of PR genes within such pathways were upregulated, whereas around $10 \%$ were downregulated (Fig. 7).

WRKY transcription factors have been reported to play an important role in plant resistance (Eulgem 2006). WRKY8 influences the crucifer-infecting Tobacco mosaic virus (TMV-cg) defense response by mediating both abscisic acid and ethylene signaling (Chen et al. 2013a). Based on our data, nearly half of WRKY transcription factors were significantly upregulated, with a 1.1- to 7.3-fold increase in expression. A heatmap of defense process genes validated these results (Supplementary Fig. S2).

TABLE 1. Specific genes information in cell-wall-related pathway at 9,12 , and 15 days postinoculation, respectively

\begin{tabular}{|c|c|c|c|c|c|c|}
\hline \multirow[b]{2}{*}{ Gene identifier } & \multicolumn{2}{|c|}{$9 \mathrm{dpi}^{\mathrm{a}}$} & \multicolumn{2}{|c|}{12 dpi } & \multicolumn{2}{|c|}{$15 \mathrm{dpi}$} \\
\hline & $\log _{2}$ (fold change) & Trends of regulation & $\log _{2}$ (fold change) & Trends of regulation & $\log _{2}$ (fold change) & Trends of regulation \\
\hline \multicolumn{7}{|c|}{ Cellulose synthesis } \\
\hline at $2 \mathrm{~g} 24630$ & -1.09763 & Down & -1.24934 & Down & -1.96844 & Down \\
\hline at1g24070 & -1.7335 & Down & -2.03652 & Down & -1.65734 & Down \\
\hline at $5 \mathrm{~g} 16190$ & -2.13355 & Down & -1.99167 & Down & -2.42748 & Down \\
\hline at4g13410 & -1.93853 & Down & -3.14795 & Down & -3.07856 & Down \\
\hline at4g31590 & -1.4456 & Down & -1.92324 & Down & -2.64772 & Down \\
\hline at5g22740 & -1.09634 & Down & -1.71385 & Down & -1.94281 & Down \\
\hline at5g03760 & -1.49523 & Down & -2.66919 & Down & -2.98299 & Down \\
\hline at4g39350 & -1.0152 & Down & -1.1048 & Down & -0.809807 & \\
\hline at5g09870 & -1.14864 & Down & -0.968827 & & -1.26934 & Down \\
\hline \multicolumn{7}{|l|}{ Cell wall protein } \\
\hline at $\lg 68725$ & -1.79001 & Down & -1.86101 & Down & -2.45361 & Down \\
\hline at5g60490 & -1.07664 & Down & -1.12628 & Down & -1.97179 & Down \\
\hline at3g52370 & -1.45045 & Down & -2.39017 & Down & -1.72635 & Down \\
\hline at3g46550 & -1.02238 & Down & -1.02835 & Down & -1.87541 & Down \\
\hline at5g06390 & -1.09031 & Down & -1.40001 & Down & -1.81449 & Down \\
\hline at5g65390 & -1.56339 & Down & -1.72986 & Down & -1.5824 & Down \\
\hline at3g11700 & -1.14563 & Down & -1.35268 & Down & -1.82186 & Down \\
\hline at5g55730 & -1.26931 & Down & -1.73121 & Down & -1.98864 & Down \\
\hline at $2 \mathrm{~g} 04780$ & -1.61843 & Down & -2.0835 & Down & -2.09742 & Down \\
\hline at5g10430 & -1.69577 & Down & -2.81834 & Down & -2.94583 & Down \\
\hline at1g03870 & -1.41825 & Down & -1.33356 & Down & -1.44982 & Down \\
\hline at4g12730 & -1.60786 & Down & -1.66258 & Down & -1.38978 & Down \\
\hline at5g44130 & -1.5675 & Down & -2.12864 & Down & -1.93975 & Down \\
\hline at $2 \mathrm{~g} 14890$ & -1.30329 & Down & -1.29551 & Down & -1.92078 & Down \\
\hline at2 $\mathrm{g} 45470$ & -2.11281 & Down & -2.71086 & Down & -3.92062 & Down \\
\hline \multicolumn{7}{|c|}{ Cell wall degradation enzyme } \\
\hline at5g62150 & 4.60138 & Up & 4.64635 & Up & 5.39635 & Up \\
\hline at5g20950 & 1.64004 & Up & 0.528356 & & 0.75202 & \\
\hline at $4 \mathrm{~g} 30270$ & 3.20631 & Up & 2.96326 & Up & 4.0286 & Up \\
\hline at5g49360 & 1.12819 & Up & 1.36208 & Up & 1.52267 & Up \\
\hline at3g54920 & 1.14378 & Up & 0.258846 & & -0.746906 & \\
\hline at $2 \mathrm{~g} 18660$ & 4.15316 & Up & 2.11973 & Up & 2.45283 & Up \\
\hline at $2 \mathrm{~g} 45220$ & 7.97132 & Up & 6.48892 & Up & 7.92552 & Up \\
\hline at3g13790 & 2.38246 & Up & 2.25579 & Up & 3.0006 & Up \\
\hline at $1 \mathrm{~g} 21250$ & 1.11909 & Up & 0.79163 & & 0.814957 & \\
\hline
\end{tabular}

${ }^{\mathrm{a}}$ dpi $=$ days postinoculation. 
Collectively, the data showed that viral infection activated plant defense pathways at all three infection stages.

To resist viral spread and multiplication, plants implement protein degradation strategies to accelerate protein metabolism (Deng et al. 2017; Zeng et al. 2004). In this study, we identified a remarkable change in autophagy-related genes: $>45 \%$ of genes in the autophagy pathway were upregulated at 9 and $15 \mathrm{dpi}$, whereas a slightly lower percentage were upregulated at $12 \mathrm{dpi}$ (Fig. 7). The ubiquitin-proteasome pathway is involved in the regulation of metabolic adaptation and the immune response (Furniss and Spoel 2015; Han et al. 2019). We found that $40 \%$ of E2 genes were upregulated at $15 \mathrm{dpi}$ (Fig. 7). Moreover, all proteins in the proteasome and cysteine protease degradation subpathways exhibited increased upregulation at 9 and $15 \mathrm{dpi}$. However, these subpathways had slightly decreased expression at 12 dpi (Fig. 7). Although some genes in the protein degradation pathway were downregulated, most were upregulated (Supplementary Fig. S2). These observations suggest that activation of the ubiquitinproteasome, autophagy, and plant defense responses are hallmarks of cellular changes associated with TSWV infection.

qRT-PCR validation of DEGs. To validate the RNA-seq data, we validated gene expression profiles using qRT-PCR. Sixteen genes from different pathways with obvious altered expression patterns, including the hormone pathway, photosynthesis pathway, WRKY transcription factors, autophagy pathway, and cell wall pathway, were selected for qRT-PCR analysis and all of these genes showed relatively high expression levels. qRT-PCR showed that the direction of change for all 16 genes was consistent with the RNAseq data (Fig. 8). For example, the qRT-PCR results showed that the fold increase in catalytic/ribulose-phosphate 3-epimerase expression in the Calvin cycle pathway was 1.2, 1.8, and 2.6 at 9, 12 , and $15 \mathrm{dpi}$, consistent with the RNA-seq data. qRT-PCR data for the WRKY 6 transcription factor were also consistent with the RNAseq data, with fold increases in expression of 1.6, 2.6, and 3.6 at 9, 12, and $15 \mathrm{dpi}$, respectively. Minor inconsistencies may have been caused by the lower sensitivity of qRT-PCR compared with RNAseq. Nevertheless, qRT-PCR analyses broadly confirmed the direction of changes in expression detected by RNA-seq analyses, indicating that the RNA-seq data were reliable.

\section{DISCUSSION}

Viruses are obligate parasites that depend on the host's machinery to multiply and spread and to repress host defense responses like other obligate parasites (Brodersen and Voinnet 2009; Dunoyer et al. 2004; Hyodo et al. 2013; Jing et al. 2016; Laliberté and Sanfacon 2010; Pallas and Garcia 2011; Sade et al. 2012; Satoh et al. 2010). Viruses may induce downregulation or upregulation of plant genes for their own benefit. By contrast, plant cells sense viral invasion and initiate a series of defense responses (Dodds and Rathjen 2010; Mandadi and Scholthof 2013). In this study, deep sequencing technology was used to characterize model plant $A$. thaliana dynamic transcriptome profiles during TSWV infection at different points over time.

Photosynthesis is arguably one of the most important biological processes and plays important roles in plant growth, development, and defense against pathogens. Many plant viruses can impair photosynthesis to regulate plant growth and development, aiding viral infection. For instance, potato virus X (SPCP1 strain) changes the photosynthetic rate by regulating PSII and

\section{Percentage of genes}

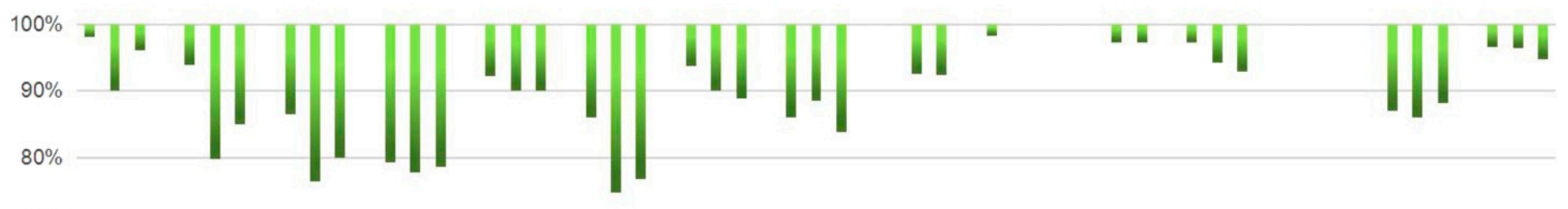

$70 \%$

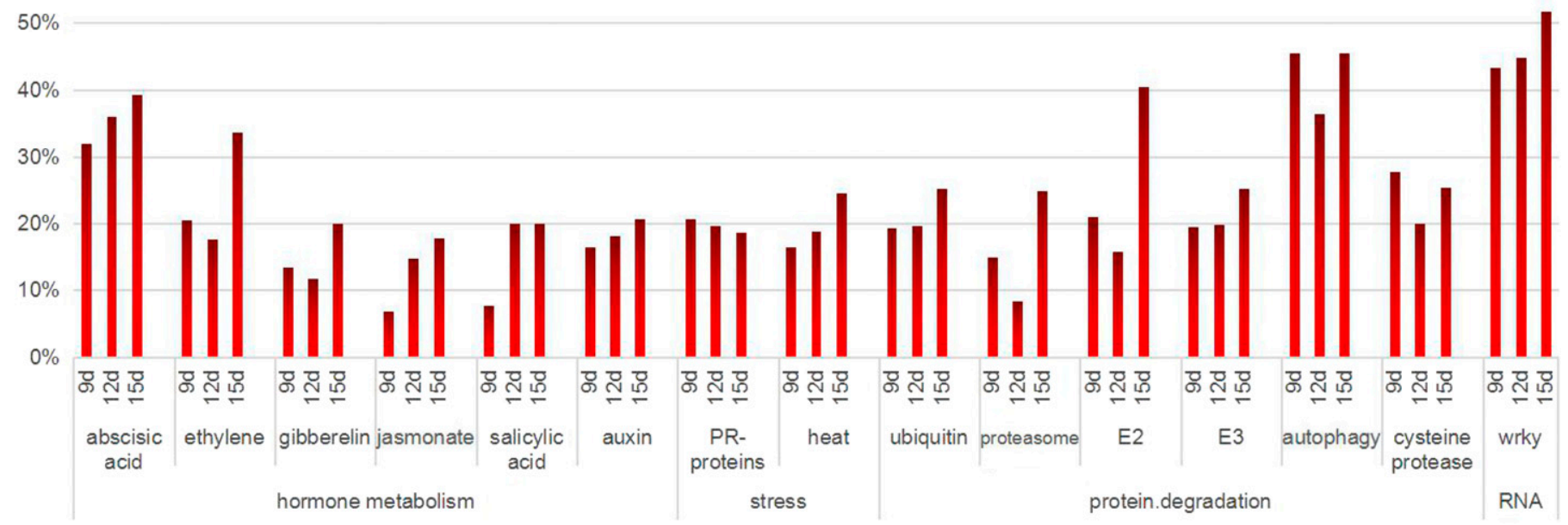

- up-regulated no variation/not expressed $=$ down-regulated

Fig. 7. Percentages of differentially expressed genes in plant defense and degradation pathways at 9 , 12, and 15 days postinoculation. Red (dark gray) indicates mostly upregulated genes in the corresponding pathway and green (light gray) indicates mostly downregulated genes in the corresponding pathway. PR = pathogenesis-related. 
carbohydrate synthesis (Cueto-Ginzo et al. 2016). Geminivirus beta $\mathrm{C} 1$ protein attacks PsbP protein, an extrinsic subunit protein within the oxygen-evolving complex of PSII, and induces symptoms by disrupting the ultrastructure and function of chloroplasts (Bhattacharyya et al. 2015). In a previous study, transcriptome analyses of chlorotic Theobroma cacao leaves infected with the fungal pathogen Moniliophthora perniciosa revealed the downregulation of photosynthesis genes (Teixeira et al. 2014). Immunogold labeling has revealed Lily mottled virus coat protein localized to chloroplasts. The overaccumulation of this protein inhibits PSII activity, causing mottling symptoms (Zhang et al. 2019). The studies described above showed correlations between photosystem damage and chlorotic symptoms; our results support these findings. We conclude that plant mottling and chlorotic symptoms in A. thaliana may be caused by PSII system damage as a result of TSWV infection. Further research at5g59220

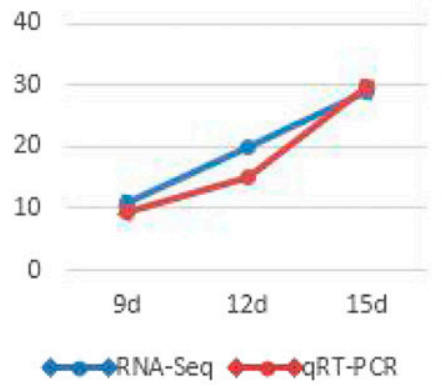

at5g17290

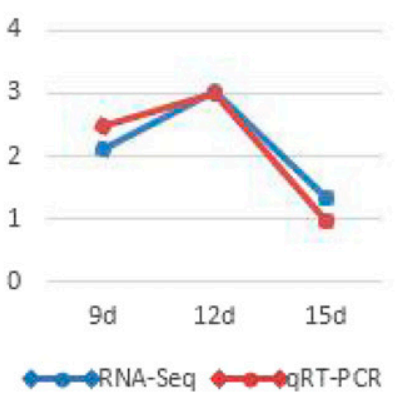

at5g35360

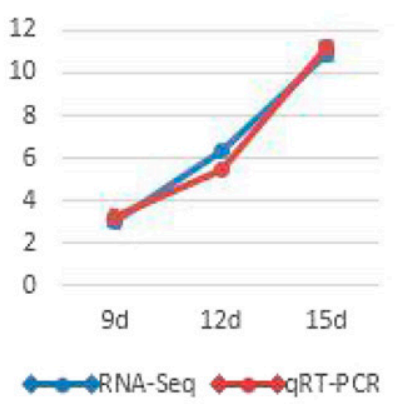

at2g04780

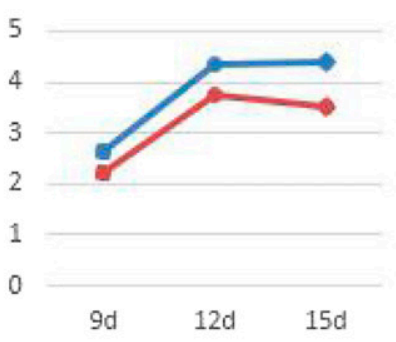

$\Leftrightarrow$ ARNA-Seq $\Leftrightarrow$ QRT-PCR at3g44300

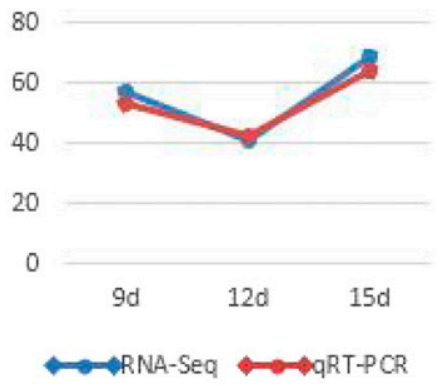

at1g62300

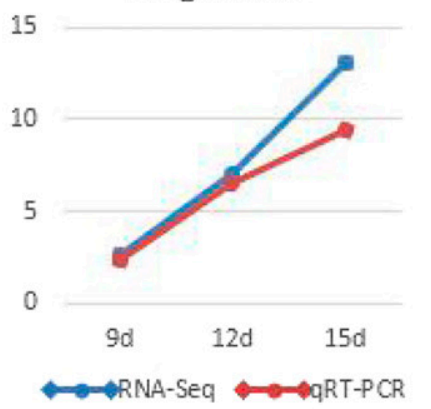

at2g30550

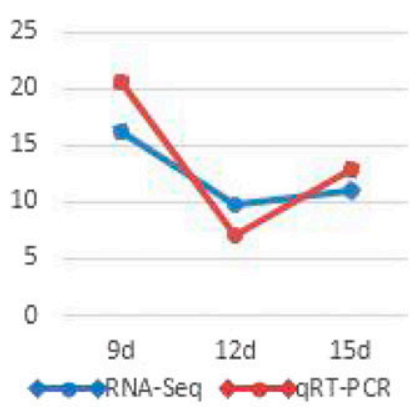

at1g32060

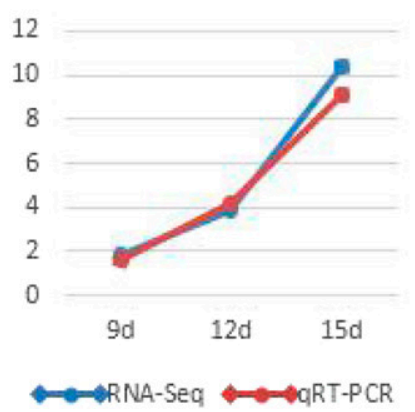

at5g43450

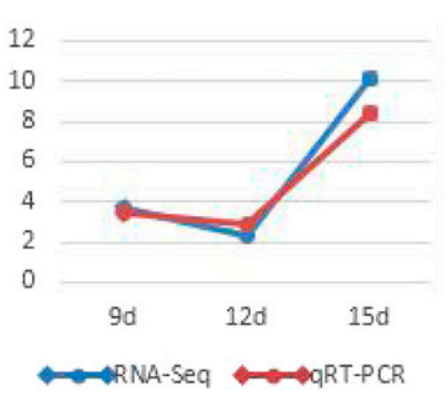

at2g30250

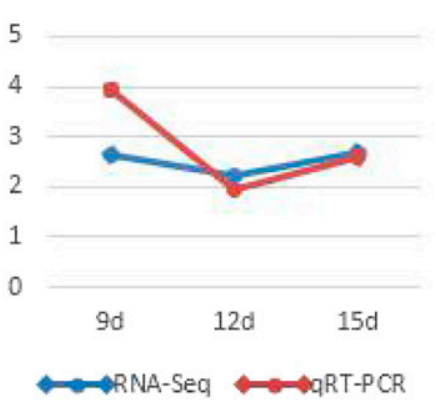

at5g03760
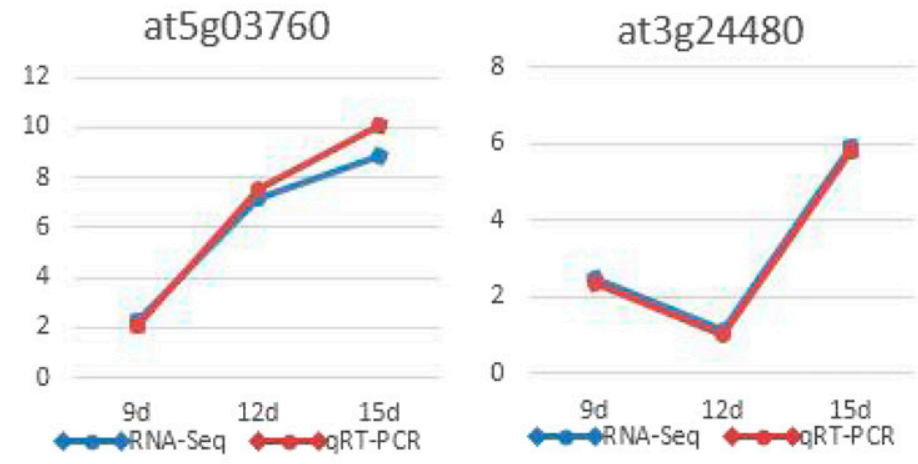

Fig. 8. Quantitative real-time (qRT)-PCR validation of 16 differentially expressed genes from different pathways. The $x$-axis represents different timepoints, and the $y$-axis represents fold change. Red (light gray) lines represent the qRT-PCR results and blue (dark gray) lines represent the RNA-sequencing (RNA-seq) results. 
is required to identify the specific viral proteins and host factors contributing to this process.

The plant cell wall is located outside the cell membrane and provides structural integrity and protection against biotic and abiotic stressors (Underwood 2012). It also plays a regulatory role in plant growth and development (Szymanski and Cosgrove 2009). The apoplastic effector PsXEG1 from Phytophthora sojae could damage the host cell wall and utilize its mutant XLP1 to avoid host defense response (Ma et al. 2017). Research on interactions between plant cell walls and viruses has revealed that cell wallrelated genes are downregulated during infection. For example, Potato virus $Y$ infection inhibits xyloglucan CesA4 catalytic activity and increases xylan deposition to reduce cell wall integrity (Allie et al. 2014; Otulak-Kozieł et al. 2018a, b). In a study on transcriptional analysis of the tomato $\mathrm{Sw}-7$ line plant response to TSWV, Padmanabhan et al. (2019) showed that callose deposition was upregulated in $\mathrm{Sw}-7$ plants but not in susceptible plants. Some cell wall enzymes, such as pectinesterase and expansin, were also found to have a different expression pattern in the $\mathrm{Sw}-7$ line and susceptible line during TSWV infection (Padmanabhan et al. 2019). In this study, most cellulose synthesis-related genes were downregulated, indicating inhibition of the cellulose synthesis process. Furthermore, some cellulases and beta-1,4-glucanases were upregulated to promote cellulose and hemicellulose degradation. The disruption of cell walls might directly facilitate viral invasion and cell-to-cell movement.

In addition, pathogens may regulate WRKYs to mediate cell wall metabolism (Li et al. 2017). We found that TSWV regulates cell wall-related genes possibly through transcription factors but also by directly influencing genes involved in cell wall synthesis and degradation. Some specific degradation enzymes involved in cell wall degradation were highly induced, which might affect the recruitment of host factors (Horn et al. 2012). These enzymes catalyze cell wall disruption to facilitate viral infection and transport.

To counteract viral infection, plants may induce PR protein expression. PR is considered the first line of defense against pathogens (Breen et al. 2016; Reiss 1998; Wang et al. 2018). TMV infection induces the expression of PR-1, PR-4, and PR-5 proteins (Wang et al. 2018). PR-5 was found to play a key role in Sw-7mediated resistance to TSWV (Padmanabhan et al. 2019) while expression of other PR proteins (PR-12 and PR-6) was also altered. In Arabidopsis species, $20 \%$ of PR proteins were upregulated, which indicates their coordinated function in resistance to TSWV infection. As discussed previously, WRKYs manipulate gene expression to initiate the defense response under biotic stress (Eulgem 2006; Eulgem and Somssich 2007; Gallou et al. 2012; Ryu et al. 2006; Yamada et al. 2007). Although WRKYs may play the essential defense roles in $A$. thaliana plants upon TSWV infection, other transcription factors such as Myb family and bZIP family take the responsibility to response TSWV infection in tomato plant (Padmanabhan et al. 2019). Notably, some bZIP family transcription factors in A. thaliana plants were also induced (Supplemental Table S4). Taken together, WRKYs and bZIPs are important host transcription factors upregulated upon TSWV infection. These genes were massively upregulated and could be used to manipulate the expression of related genes, such as those for PR proteins and cell wall-related proteins. The ubiquitin and autophagy pathways play a role in protein degradation, and many studies have shown that these pathways are involved in host resistance to viral infection (Verchot 2016). The E2 ligase family can mediate plant immunityassociated ROS and suppress multiple immunity-associated programmed cell death (PCD) in $N$. benthamiana (Zhou and Zeng 2017). TYLCV and Turnip mosaic virus infections induce upregulation of autophagy pathway-related genes to inhibit viral infection (Hafrén et al. 2018; Miozzi et al. 2014). Plant transcriptome rearrangement is a complex process during viral infection and includes regulation of photosystems, cell wall- related metabolism, hormones, and defense responses. Analyses of this phenomenon at the system, pathway, or even gene-specific level will provide deeper insight into TSWV-host interactions and symptom development.

\section{LITERATURE CITED}

Allie, F., Pierce, E. J., Okoniewski, M. J., and Rey, C. 2014. Transcriptional analysis of South African cassava mosaic virus-infected susceptible and tolerant landraces of cassava highlights differences in resistance, basal defense and cell wall associated genes during infection. BMC Genomics 15:1006.

Aparicio, F., Thomas, C. L., Lederer, C., Niu, Y., Wang, D., and Maule, A. J. 2005. Virus induction of heat shock protein 70 reflects a general response to protein accumulation in the plant cytosol. Plant Physiol. 138:529-536.

Asari, S., Tarkowska, D., Rolcik, J., Novak, O., Palmero, D. V., Bejai, S., and Meijer, J. 2017. Analysis of plant growth-promoting properties of Bacillus amyloliquefaciens UCMB5113 using Arabidopsis thaliana as host plant. Planta 245:15-30.

Baccelli, I., and Mauch-Mani, B. 2016. Beta-aminobutyric acid priming of plant defense: The role of ABA and other hormones. Plant Mol. Biol. 91: 703-711.

Benjamini, Y., and Hochberg, Y. 1995. Controlling the false discovery rate: A practical and powerful approach to multiple testing. J R Stat Soc Ser. B. 57: 289-300.

Bhattacharyya, D., Gnanasekaran, P., Kumar, R. K., Kushwaha, N. K., Sharma, V. K., Yusuf, M. A., and Chakraborty, S. 2015. A geminivirus betasatellite damages the structural and functional integrity of chloroplasts leading to symptom formation and inhibition of photosynthesis. J. Exp. Bot. 66: 5881-5895.

Breen, S., Williams, S. J., Winterberg, B., Kobe, B., and Solomon, P. S. 2016. Wheat PR-1 proteins are targeted by necrotrophic pathogen effector proteins. Plant J. 88:13-25.

Brodersen, P., and Voinnet, O. 2009. Revisiting the principles of microRNA target recognition and mode of action. Nat. Rev. Mol. Cell Biol. 10: 141-148.

Catoni, M., Miozzi, L., Fiorilli, V., Lanfranco, L., and Accotto, G. P. 2009. Comparative analysis of expression profiles in shoots and roots of tomato systemically infected by Tomato spotted wilt virus reveals organ-specific transcriptional responses. Mol. Plant-Microbe Interact. 22:1504-1513.

Chandrasekaran, M., and Chun, S. C. 2016. Expression of PR-protein genes and induction of defense-related enzymes by Bacillus subtilis CBR05 in tomato (Solanum lycopersicum) plants challenged with Erwinia carotovora subsp. carotovora. Biosci. Biotechnol. Biochem. 80:2277-2283.

Chen, L. G., Zhang, L. P., Li, D. B., Wang, F., and Yu, D. Q. 2013a. WRKY8 transcription factor functions in the TMV-cg defense response by mediating both abscisic acid and ethylene signaling in Arabidopsis. Proc. Natl. Acad. Sci. USA 110:E1963-E1971.

Choi, H., Jo, Y., Lian, S., Jo, K. M., Chu, H., Yoon, J. Y., Choi, S. K., Kim, K. H., and Cho, W. K. 2015. Comparative analysis of chrysanthemum transcriptome in response to three RNA viruses: Cucumber mosaic virus, Tomato spotted wilt virus and Potato virus X. Plant Mol. Biol. 88:233-248.

Cueto-Ginzo, A. I., Serrano, L., Bostock, R. M., Ferrio, J. P., Rodriguez, R., Arcal, L., Achon, M. A., Falcioni, T., Luzuriaga, W. P., and Medina, V. 2016. Salicylic acid mitigates physiological and proteomic changes induced by the SPCP1 strain of Potato virus $X$ in tomato plants. Physiol. Mol. Plant Pathol. 93:1-11.

De Vos, M., Van Oosten, V. R., Van Poecke, R. M., Van Pelt, J. A., Pozo, M. J., Mueller, M. J., Buchala, A. J., Metraux, J. P., Van Loon, L. C., Dicke, M., and Pieterse, C. M. 2005. Signal signature and transcriptome changes of Arabidopsis during pathogen and insect attack. Mol. Plant-Microbe Interact. 18:923-937.

Deng, F. Y., Guo, T. W., Lefebvre, M., Scaglione, S., Antico, C. J., Jing, T., Yang, X., Shan, W. X., and Ramonell, K. M. 2017. Expression and regulation of ATL9, an E3 ubiquitin ligase involved in plant defense. PLoS One 12:e0188458.

Diaz-Vivancos, P., Clemente-Moreno, M. J., Rubio, M., Olmos, E., Garcia, J. A., Martinez-Gomez, P., and Hernandez, J. A. 2008. Alteration in the chloroplastic metabolism leads to ROS accumulation in pea plants in response to Plum pox virus. J. Exp. Bot. 59:2147-2160.

Dodds, P. N., and Rathjen, J. P. 2010. Plant immunity: Towards an integrated view of plant-pathogen interactions. Nat. Rev. Genet. 11:539-548.

Dunoyer, P., Thomas, C., Harrison, S., Revers, F., and Maule, A. 2004. A cysteine-rich plant protein potentiates potyvirus movement through an interaction with the virus genome-linked protein VPg. J. Virol. 78:2301-2309.

Edelbaum, O., Sher, N., Rubinstein, M., Novick, D., Tal, N., Moyer, M., Ward, E., Ryals, J., and Sela, I. 1991. Two antiviral proteins, gp35 and gp22, 
correspond to $\beta$-1,3-glucanase and an isoform of PR-5. Plant Mol. Biol. 17: 171-173.

Eulgem, T. 2006. Dissecting the WRKY web of plant defense regulators. PLoS Pathog. 2:e126.

Eulgem, T., and Somssich, I. E. 2007. Networks of WRKY transcription factors in defense signaling. Curr. Opin. Plant Biol. 10:366-371.

Feng, Z., Chen, X., Bao, Y., Dong, J., Zhang, Z., and Tao, X. 2013. Nucleocapsid of Tomato spotted wilt tospovirus forms mobile particles that traffic on an actin/endoplasmic reticulum network driven by myosin XI-K. New Phytol. 200:1212-1224.

Feng, Z., Xue, F., Xu, M., Chen, X., Zhao, W., Garcia-Murria, M. J., Mingarro, I., Liu, Y., Huang, Y., Jiang, L., Zhu, M., and Tao, X. 2016. The ERmembrane transport system is critical for intercellular trafficking of the NSm movement protein and Tomato spotted wilt tospovirus. PLoS Pathog 12:e1005443.

Furniss, J. J., and Spoel, S. H. 2015. Cullin-RING ubiquitin ligases in salicylic acid-mediated plant immune signaling. Front. Plant Sci. 6:154.

Gallou, A., Declerck, S., and Cranenbrouck, S. 2012. Transcriptional regulation of defence genes and involvement of the WRKY transcription factor in arbuscular mycorrhizal potato root colonization. Funct. Integr. Genomics 12:183-198.

Geng, C., Wang, H. Y., Liu, J., Yan, Z. Y., Tian, Y. P., Yuan, X. F., Gao, R., and Li, X. D. 2017. Transcriptomic changes in Nicotiana benthamiana plants inoculated with the wild-type or an attenuated mutant of Tobacco vein banding mosaic virus. Mol. Plant Pathol. 18:1175-1188.

German, T. L., Adkins, S., Witherell, A., Richmond, K. E., Knaack, W. R., and Willis, D. K. 1995. Infection of Arabidopsis thaliana ecotype Columbia by Tomato spotted wilt virus. Plant Mol. Biol. Rep. 13:110-117.

Gilbertson, R. L., Batuman, O., Webster, C. G., and Adkins, S. 2015. Role of the insect supervectors Bemisia tabaci and Frankliniella occidentalis in the emergence and global spread of plant viruses. Annu. Rev. Virol. 2: 67-93.

Hafrén, A., Ustun, S., Hochmuth, A., Svenning, S., Johansen, T., and Hofius, D. 2018. Turnip mosaic virus counteracts selective autophagy of the viral silencing suppressor HCpro. Plant Physiol. 176:649-662.

Han, P. L., Dong, Y. H., Gu, K. D., Yu, J. Q., Hu, D. G., and Hao, Y. J. 2019. The apple U-box E3 ubiquitin ligase MdPUB29 contributes to activate plant immune response to the fungal pathogen Botryosphaeria dothidea. Planta 249:1177-1188.

Hedil, M., de Ronde, D., and Kormelink, R. 2017. Biochemical analysis of NSs from different tospoviruses. Virus Res. 242:149-155.

Hedil, M., Sterken, M. G., de Ronde, D., Lohuis, D., and Kormelink, R. 2015. Analysis of tospovirus NSs proteins in suppression of systemic silencing. PLoS One 10:e0134517.

Horn, S. J., Vaaje-Kolstad, G., Westereng, B., and Eijsink, V. G. 2012. Novel enzymes for the degradation of cellulose. Biotechnol. Biofuels 5:45.

Hu, Z. Z., Feng, Z. K., Zhang, Z. J., Liu, Y. B., and Tao, X. R. 2011. Complete genome sequence of a tomato spotted wilt virus isolate from China and comparison to other TSWV isolates of different geographic origin. Arch. Virol. 156:1905-1908.

Huang, P. Y., Catinot, J., and Zimmerli, L. 2016. Ethylene response factors in Arabidopsis immunity. J. Exp. Bot. 67:1231-1241.

Hyodo, K., Mine, A., Taniguchi, T., Kaido, M., Mise, K., Taniguchi, H., and Okuno, T. 2013. ADP ribosylation factor 1 plays an essential role in the replication of a plant RNA virus. J. Virol. 87:163-176.

Jing, M., Guo, B., Li, H., Yang, B., Wang, H., Kong, G., Zhao, Y., Xu, H., Wang, Y., Ye, W., Dong, S., Qiao, Y., Tyler, B. M., Ma, W., and Wang, Y. 2016. A Phytophthora sojae effector suppresses endoplasmic reticulum stress-mediated immunity by stabilizing plant binding immunoglobulin proteins. Nat. Commun. 7:11685.

Kachroo, A., and Kachroo, P. 2007. Salicylic acid-, jasmonic acid- and ethylene-mediated regulation of plant defense signaling. Genet. Eng. (N. Y.) 28:55-83.

Ke, X., Yin, Z., Song, N., Dai, Q., Voegele, R. T., Liu, Y., Wang, H., Gao, X., Kang, Z., and Huang, L. 2014. Transcriptome profiling to identify genes involved in pathogenicity of Valsa mali on apple tree. Fungal Genet. Biol. 68:31-38.

Laliberté, J. F., and Sanfacon, H. 2010. Cellular remodeling during plant virus infection. Annu. Rev. Phytopathol. 48:69-91.

Langmead, B., and Salzberg, S. 2012. Fast gapped-read alignment with Bowtie 2. Nat. Methods 9:357-359.

Li, J., Feng, Z., Wu, J., Huang, Y., Lu, G., Zhu, M., Wang, B., Mao, X., and Tao, X. 2015. Structure and function analysis of nucleocapsid protein of Tomato spotted wilt virus interacting with RNA using homology modeling. J. Biol. Chem. 290:3950-3961.

Li, J., Zhong, R., and Palva, E. T. 2017. WRKY70 and its homolog WRKY54 negatively modulate the cell wall-associated defenses to necrotrophic pathogens in Arabidopsis. PLoS One 12:e0183731.
Li, R., Weldegergis, B. T., Li, J., Jung, C., Qu, J., Sun, Y., Qian, H., Tee, C., van Loon, J. J., Dicke, M., Chua, N. H., Liu, S. S., and Ye, J. 2014. Virulence factors of geminivirus interact with MYC2 to subvert plant resistance and promote vector performance. Plant Cell 26: 4991-5008.

Lu, R., Malcuit, I., Moffett, P., Ruiz, M. T., Peart, J., Wu, A. J., Rathjen, J. P., Bendahmane, A., Day, L., and Baulcombe, D. C. 2003. High throughput virus-induced gene silencing implicates heat shock protein 90 in plant disease resistance. EMBO J. 22:5690-5699.

Luan, J. B., Li, J. M., Varela, N., Wang, Y. L., Li, F. F., Bao, Y. Y., Zhang, C. X., Liu, S. S., and Wang, X. W. 2011. Global analysis of the transcriptional response of whitefly to Tomato yellow leaf curl China virus reveals the relationship of coevolved adaptations. J. Virol. 85:3330-3340.

Ma, Z., Zhu, L., Song, T., Wang, Y., Zhang, Q., Xia, Y., Qiu, M., Lin, Y., Li, H., Kong, L., Fang, Y., Ye, W., Dong, S., Zheng, X., Tyler, B. M., and Wang, Y. 2017. A paralogous decoy protects Phytophthora sojae apoplastic effector PsXEG1 from a host inhibitor. Science 355:710-714.

Mandadi, K. K., and Scholthof, K. B. 2013. Plant immune responses against viruses: How does a virus cause disease? Plant Cell 25:1489-1505.

Martínez-Pérez, M., Aparicio, F., Lopez-Gresa, M. P., Belles, J. M., Sanchez-Navarro, J. A., and Pallas, V. 2017. Arabidopsis m(6)A demethylase activity modulates viral infection of a plant virus and the m(6)A abundance in its genomic RNAs. Proc. Natl. Acad. Sci. U.S.A. 114: $10755-10760$

Mauch-Mani, B., and Flors, V. 2009. The ATAF1 transcription factor: At the convergence point of ABA-dependent plant defense against biotic and abiotic stresses. Cell Res. 19:1322-1323.

Miozzi, L., Napoli, C., Sardo, L., and Accotto, G. P. 2014. Transcriptomics of the interaction between the monopartite phloem-limited geminivirus Tomato yellow leaf curl Sardinia virus and Solanum lycopersicum highlights a role for plant hormones, autophagy and plant immune system fine tuning during infection. PLoS One 9:e89951.

Mochizuki, T., Ogata, Y., Hirata, Y., and Ohki, S. T. 2014. Quantitative transcriptional changes associated with chlorosis severity in mosaic leaves of tobacco plants infected with Cucumber mosaic virus. Mol. Plant Pathol. 15:242-254.

Oliver, J. E., and Whitfield, A. E. 2016. The genus Tospovirus: Emerging bunyaviruses that threaten food security. Annu. Rev. Virol. 3:101-124.

Otulak-Kozieł, K., Koziel, E., and Bujarski, J. J. 2018a. Spatiotemporal changes in xylan-1/xyloglucan and xyloglucan xyloglucosyl transferase (XTH-Xet5) as a step-in of ultrastructural cell wall remodelling in potatoPotato virus $Y$ (PVY $\left.{ }^{\mathrm{NTN}}\right)$ hypersensitive and susceptible reaction. Int. J. Mol. Sci. 19:2287.

Otulak-Kozieł, K., Koziel, E., and Lockhart, B. E. L. 2018b. Plant cell wall dynamics in compatible and incompatible potato response to infection caused by Potato virus $Y\left(\mathrm{PVY}^{\mathrm{NTN}}\right)$. Int. J. Mol. Sci. 19:862.

Padmanabhan, C., Ma, Q., Shekasteband, R., Stewart, K. S., Hutton, S. F., Scott, J. W., Fei, Z., and Ling, K. S. 2019. Comprehensive transcriptome analysis and functional characterization of PR-5 for its involvement in tomato Sw-7 resistance to Tomato spotted wilt tospovirus. Sci. Rep. 9:7673.

Pallas, V., and Garcia, J. A. 2011. How do plant viruses induce disease? Interactions and interference with host components. J. Gen. Virol. 92: 2691-2705.

Petek, M., Rotter, A., Kogovsek, P., Baebler, S., Mithofer, A., and Gruden, K. 2014. Potato virus $Y$ infection hinders potato defence response and renders plants more vulnerable to Colorado potato beetle attack. Mol. Ecol. 23: 5378-5391.

Prasch, C. M., and Sonnewald, U. 2013. Simultaneous application of heat, drought, and virus to Arabidopsis plants reveals significant shifts in signaling networks. Plant Physiol. 162:1849-1866.

Prins, M., and Goldbach, R. 1998. The emerging problem of tospovirus infection and nonconventional methods of control. Trends Microbiol. 6:31-35.

Quecini, V., Lopes, M. L., Pacheco, F. T. H., and Ongarelli, M. G. 2007. Tomato spotted wilt virus triggers specific and shared defense mechanisms in hypersensitive and susceptible Solanaceae hosts. Physiol. Mol. Plant Pathol. 70:189-197

Raad, M., Glare, T. R., Brochero, H. L., Muller, C., and Rostas, M. 2019. Transcriptional reprogramming of Arabidopsis thaliana defence pathways by the entomopathogen Beauveria bassiana correlates with resistance against a fungal pathogen but not against insects [published corrigendum appears in Front. Microbiol. 10:1481]. Front. Microbiol. 10:615.

Ramesh, S. V., Williams, S., Kappagantu, M., Mitter, N., and Pappu, H. R. 2017. Transcriptome-wide identification of host genes targeted by Tomato spotted wilt virus-derived small interfering RNAs. Virus Res. 238:13-23.

Reiss, E. 1998. PR (pathogenesis-related) proteins in the host-pathogen system barley-Drechslera teres. Beitr. Zur Zuchtungsforschung 4:4-5.

Rotenberg, D., Jacobson, A. L., Schneweis, D. J., and Whitfield, A. E. 2015. Thrips transmission of tospoviruses. Curr. Opin. Virol. 15:80-89. 
Rubio, M., Rodriguez-Moreno, L., Ballester, A. R., de Moura, M. C., Bonghi, C., Candresse, T., and Martinez-Gomez, P. 2015. Analysis of gene expression changes in peach leaves in response to Plum pox virus infection using RNA-seq. Mol. Plant Pathol. 16:164-176.

Ryu, H. S., Han, M., Lee, S. K., Cho, J. I., Ryoo, N., Heu, S., Lee, Y. H., Bhoo, S. H., Wang, G. L., Hahn, T. R., and Jeon, J. S. 2006. A comprehensive expression analysis of the WRKY gene superfamily in rice plants during defense response. Plant Cell Rep. 25:836-847.

Sade, D., Eybishtz, A., Gorovits, R., Sobol, I., and Czosnek, H. 2012. A developmentally regulated lipocalin-like gene is overexpressed in Tomato yellow leaf curl virus-resistant tomato plants upon virus inoculation, and its silencing abolishes resistance. Plant Mol. Biol. 80:273-287.

Sade, D., Shriki, O., Cuadros-Inostroza, A., Tohge, T., Semel, Y., Haviv, Y., Willmitzer, L., Fernie, A. R., Czosnek, H., and Brotman, Y. 2014. Comparative metabolomics and transcriptomics of plant response to Tomato yellow leaf curl virus infection in resistant and susceptible tomato cultivars. Metabolomics 11:81-97.

Saeed, A. I., Sharov, V., White, J., Li, J., Liang, W., Bhagabati, N., Braisted, J., Klapa, M., Currier, T., Thiagarajan, M., Sturn, A., Snuffin, M., Rezantsev, A., Popov, D., Ryltsov, A., Kostukovich, E., Borisovsky, I., Liu, Z., Vinsavich, A., Trush, V., and Quackenbush, J. 2003. TM4: A free, opensource system for microarray data management and analysis. Biotechniques 34:374-378.

Satoh, K., Kondoh, H., Sasaya, T., Shimizu, T., Choi, I. R., Omura, T., and Kikuchi, S. 2010. Selective modification of rice (Oryza sativa) gene expression by Rice stripe virus infection. J. Gen. Virol. 91:294-305.

Schneweis, D. J., Whitfield, A. E., and Rotenberg, D. 2017. Thrips developmental stage-specific transcriptome response to Tomato spotted wilt virus during the virus infection cycle in Frankliniella occidentalis, the primary vector. Virology 500:226-237.

Scholthof, K. B., Adkins, S., Czosnek, H., Palukaitis, P., Jacquot, E., Hohn, T., Hohn, B., Saunders, K., Candresse, T., Ahlquist, P., Hemenway, C., and Foster, G. D. 2011. Top 10 plant viruses in molecular plant pathology. Mol. Plant Pathol. 12:938-954.

Senthil, G., Liu, H., Puram, V. G., Clark, A., Stromberg, A., and Goodin, M. M. 2005. Specific and common changes in Nicotiana benthamiana gene expression in response to infection by enveloped viruses. J. Gen. Virol. 86: 2615-2625.

Shi, X. B., Pan, H. P., Xie, W., Wu, Q. J., Wang, S. L., Liu, Y., Fang, Y., Chen, G., Gao, X. W., and Zhang, Y. J. 2013. Plant virus differentially alters the plant's defense response to its closely related vectors. PLoS One 8:e83520.

Su, Q., Mescher, M. C., Wang, S. L., Chen, G., Xie, W., Wu, Q. J., Wang, W. K., and Zhang, Y. J. 2016. Tomato yellow leaf curl virus differentially influences plant defence responses to a vector and a non-vector herbivore. Plant Cell Environ. 39:597-607.

Szymanski, D. B., and Cosgrove, D. J. 2009. Dynamic coordination of cytoskeletal and cell wall systems during plant cell morphogenesis. Curr. Biol. 19:R800-R811.

Teixeira, P. J., Thomazella, D. P., Reis, O., do Prado, P. F., do Rio, M. C., Fiorin, G. L., Jose, J., Costa, G. G., Negri, V. A., Mondego, J. M., Mieczkowski, P., and Pereira, G. A. 2014. High-resolution transcript profiling of the atypical biotrophic interaction between Theobroma cacao and the fungal pathogen Moniliophthora perniciosa. Plant Cell 26:4245-4269.

Trapnell, C., Pachter, L., and Salzberg, S. L. 2009. TopHat: Discovering splice junctions with RNA-seq. Bioinformatics 25:1105-1111.

Trapnell, C., Williams, B. A., Pertea, G., Mortazavi, A., Kwan, G., van Baren, M. J., Salzberg, S. L., Wold, B. J., and Pachter, L. 2010. Transcript assembly and quantification by RNA-seq reveals unannotated transcripts and isoform switching during cell differentiation. Nat. Biotechnol. 28:511-515.

Turina, M., Kormelink, R., and Resende, R. O. 2016. Resistance to tospoviruses in vegetable crops: Epidemiological and molecular aspects. Annu. Rev. Phytopathol. 54:347-371.

Underwood, W. 2012. The plant cell wall: A dynamic barrier against pathogen invasion. Front. Plant Sci. 3:85.
Verchot, J. 2016. Plant virus infection and the ubiquitin proteasome machinery: Arms race along the endoplasmic reticulum. Viruses 8:E314.

Wang, J., and Liu, J. H. 2009. Change in free polyamine contents and expression profiles of two polyamine biosynthetic genes in citrus embryogenic callus under abiotic stresses. Biotechnol Biotec Eq. 23:1289-1293.

Wang, L. L., Wang, X. R., Wei, X. M., Huang, H., Wu, J. X., Chen, X. X., Liu, S. S., and Wang, X. W. 2016. The autophagy pathway participates in resistance to Tomato yellow leaf curl virus infection in whiteflies. Autophagy 12:1560-1574.

Wang, Q., Han, C., Ferreira, A. O., Yu, X., Ye, W., Tripathy, S., Kale, S. D., Gu, B., Sheng, Y., Sui, Y., Wang, X., Zhang, Z., Cheng, B., Dong, S., Shan, W., Zheng, X., Dou, D., Tyler, B. M., and Wang, Y. 2011. Transcriptional programming and functional interactions within the Phytophthora sojae RXLR effector repertoire. Plant Cell 23:2064-2086.

Wang, R. Y., Wang, S. S., Pan, W. D., Li, Q. C., Xia, Z. L., Guan, E., Zheng, M. Q., Pang, G. Z., Yang, Y. J., and Yi, Z. J. 2018. Strategy of tobacco plant against black shank and Tobacco mosaic virus infection via induction of PR-1, PR-4 and PR-5 proteins assisted by medicinal plant extracts. Physiol. Mol. Plant Pathol. 101:127-145.

Xu, Y., Zhou, W., Zhou, Y., Wu, J., and Zhou, X. 2012. Transcriptome and comparative gene expression analysis of Sogatella furcifera (Horvath) in response to Southern rice black-streaked dwarf virus. PLoS One 7: e36238.

Yamada, K., Chujo, T., Andoh, S., Minami, E., Shibuya, N., Okada, K., Nojiri, H., and Yamane, H. 2007. Characterization of elicitor-responsive WRKY transcription factors involved in regulation of expressions of defenseresponse genes in rice. Plant Cell Physiol. 48:S247.

Yates, S. A., Swain, M. T., Hegarty, M. J., Chernukin, I., Lowe, M., Allison, G. G., Ruttink, T., Abberton, M. T., Jenkins, G., and Skot, L. 2014. De novo assembly of red clover transcriptome based on RNA-seq data provides insight into drought response, gene discovery and marker identification. BMC Genomics 15:453.

Ye, W., Wang, X., Tao, K., Lu, Y., Dai, T., Dong, S., Dou, D., Gijzen, M., and Wang, Y. 2011. Digital gene expression profiling of the Phytophthora sojae transcriptome. Mol. Plant-Microbe Interact. 24:1530-1539.

Yu, L. J., Luo, Y. F., Liao, B., Xie, L. J., Chen, L., Xiao, S., Li, J. T., Hu, S. N., and Shu, W. S. 2012. Comparative transcriptome analysis of transporters, phytohormone and lipid metabolism pathways in response to arsenic stress in rice (Oryza sativa). New Phytol. 195:97-112.

Zeng, L. R., Qu, S. H., Bordeos, A., Yang, C. W., Baraoidan, M., Yan, H. Y., Xie, Q., Nahm, B. H., Leung, H., and Wang, G. L. 2004. Spotted leaf11, a negative regulator of plant cell death and defense, encodes a U-box/ armadillo repeat protein endowed with E3 ubiquitin ligase activity. Plant Cell 16:2795-2808.

Zhang, D. W., Deng, X. G., Fu, F. Q., and Lin, H. H. 2015. Induction of plant virus defense response by brassinosteroids and brassinosteroid signaling in Arabidopsis thaliana. Planta 241:875-885.

Zhang, Y. B., Wang, Y. J., Xie, Z. K., Wang, R. Y., Yang, G., Guo, Z. H., and Qiu, Y. 2019. A study of viral coat protein accumulation in lily chloroplasts from mixed virus infections of Lily mottle virus and Cucumber mosaic virus. Plant Pathol. 68:261-268.

Zhang, Z., Zhang, P., Li, W., Zhang, J., Huang, F., Yang, J., Bei, Y., and Lu, Y. 2013. De novo transcriptome sequencing in Frankliniella occidentalis to identify genes involved in plant virus transmission and insecticide resistance. Genomics 101:296-305.

Zhou, B. J., and Zeng, L. R. 2017. Elucidating the role of highly homologous Nicotiana benthamiana ubiquitin E2 gene family members in plant immunity through an improved virus-induced gene silencing approach. Plant Methods 13:59.

Zhu, M., van Grinsven, I. L., Kormelink, R., and Tao, X. 2019. Paving the way to tospovirus infection: Multilined interplays with plant innate immunity. Annu. Rev. Phytopathol. 57:41-62. 